\title{
Global Climate and Ocean Circulation on an Aquaplanet Ocean-Atmosphere General Circulation Model
}

\author{
Robin S. SMith \\ Southampton Oceanography Centre, Southampton, United Kingdom, and Max-Planck Institute for Meteorology, Hamburg, Germany \\ Clotilde Dubois \\ Southampton Oceanography Centre, Southampton, United Kingdom \\ Jochem MAROTZKe \\ Max-Planck Institute for Meteorology, Hamburg, Germany
}

(Manuscript received 15 July 2005, in final form November 2005)

\begin{abstract}
A low-resolution coupled ocean-atmosphere general circulation model (OAGCM) is used to study the characteristics of the large-scale ocean circulation and its climatic impacts in a series of global coupled aquaplanet experiments. Three configurations, designed to produce fundamentally different ocean circulation regimes, are considered. The first has no obstruction to zonal flow, the second contains a low barrier that blocks zonal flow in the ocean at all latitudes, creating a single enclosed basin, while the third contains a gap in the barrier to allow circumglobal flow at high southern latitudes.

Warm greenhouse climates with a global average air surface temperature of around $27^{\circ} \mathrm{C}$ result in all cases. Equator-to-pole temperature gradients are shallower than that of a current climate simulation. While changes in the land configuration cause regional changes in temperature, winds, and rainfall, heat transports within the system are little affected. Inhibition of all ocean transport on the aquaplanet leads to a reduction in global mean surface temperature of $8^{\circ} \mathrm{C}$, along with a sharpening of the meridional temperature gradient. This results from a reduction in global atmospheric water vapor content and an increase in tropical albedo, both of which act to reduce global surface temperatures.

Fitting a simple radiative model to the atmospheric characteristics of the OAGCM solutions suggests that a simpler atmosphere model, with radiative parameters chosen a priori based on the changing surface configuration, would have produced qualitatively different results. This implies that studies with reduced complexity atmospheres need to be guided by more complex OAGCM results on a case-by-case basis.
\end{abstract}

\section{Introduction}

The earth system is a complex one, with processes and feedbacks that function over time scales ranging from minutes to millennia, and spatial scales ranging from centimetres to hundred of kilometers. This complexity, along with our inability to conduct controlled experiments with the real earth system, has led to the development of ever more sophisticated climate models (e.g., Gordon et al. 2000; Roeckner et al. 2003;

Corresponding author address: Dr. Robin S. Smith, NCASClimate, Department of Meteorology, University of Reading, Reading RG6 6BB, United Kingdom.

E-mail: r.s.smith@reading.ak.uk
Marsland et al. 2003), capable of an ever-increasing suite of feedbacks and interactions between components. The computational expense of integrating these models, however, restricts their use so these models are generally only applied to questions of the current, future, or past earth climate - a small number of the limitless "climate" configurations imaginable. More idealized and general studies are done with simpler, less comprehensive models, limiting what we can learn about the wide range of feedbacks and processes that function in our climate system.

The oceans play an important role in the climate system, acting both as a heat buffer to mitigate seasonal temperature changes in the atmosphere and as a transport system, moving heat around on a global scale. A 
slow, geographically extensive feature such as the global ocean heat transport (OHT) has many potential feedbacks and interactions with the rest of the system. The meridional heat transport carried by the ocean is an important component of the earth's heat budget (Trenberth and Caron 2001) and changes in the strength of its thermohaline component are thought to have played a central role in significant, and sometimes abrupt, climate changes throughout the earth's history (e.g., Broecker et al. 1985; Heinrich 1988; McManus et al. 2004).

The effects of changing the ocean circulation and transports have been looked at in a plethora of studies, dating from the very first ocean modeling experiments, although the wider impact of these changes in the whole climate system has only really been addressed more recently with the widespread advent of coupled models. Studies have been conducted both in realistic settings [from Bryan et al. (1975) to meridional overturning circulation (MOC) shutdown experiments in Houghton et al. (2001)] and in more idealized configurations (Bryan 1986; Cox 1989; Marotzke and Willebrand 1991; Bjornsson and Toggweiler 2001). These, and many other studies, have shown the large-scale ocean circulation to be a system with different modes of operation, sensitive to changes in surface forcings and basin configuration, and capable of significant impact on the rest of the climate.

Idealized experiments are usually conducted with models that also simplify the processes and feedbacks that they can represent. The philosophy behind such studies is not to produce highly realistic simulations of every aspect of the climate, but to highlight and explore some basic processes and how they fit together. In the case of ocean transport and climate, idealized studies often use an uncoupled ocean, or a simplified energy balance atmosphere with specified winds and moisture transports (e.g., Weaver et al. 2001). The complexity and coupled nature of the climate system, however, means that the noninteractivity of these boundary conditions clearly neglects important feedbacks, even when focusing on one process (e.g., how a changed OHT can affect the rest of the system).

Here, we follow the example of the simplified experiments, but apply a model complex enough to more fully represent coupled processes in the system. Following the ethos of Neale and Hoskins (2000), we apply a fullfeatured coupled ocean-atmosphere general circulation model (OAGCM) to an aquaplanet scenario, altering the ocean circulation by means of low physical barriers that block the ocean flow but have no direct physical impact on the atmosphere. We do not believe that such scenarios have been investigated within a coupled
OAGCM before. We investigate physically possible interactions of the ocean-atmosphere system that might not be displayed by the use of such a model in a "standard" configuration, tuned to reproduce the current climate, or a reduced model incapable of such richness of behavior. Specifically, we use our very idealized setups to address some very basic issues of how changing the ocean circulation can impact on the heat transported in the ocean, how this can feed back into the wider climate, and to what degree changes in ocean heat transport are compensated for by the atmospheric energy transports.

The paper is organized as follows: a description of the model (section 2) and the experimental setups will be given (section 3 ), and the resulting climates will be outlined and analyzed with reference to a simple atmospheric radiative model in section 4 . The effect of the complete inhibition of OHT in the initial aquaplanet scenario will then be addressed in section 5, as well as the climatic differences attributable to the changed oceanic circulation for the other scenarios (section 6). A more general discussion of the results then follows, finishing with the conclusions and an appendix showing details of the model's control simulation of modern climate.

\section{The model}

A low-resolution version of the Fast Ocean, Rapid Troposphere Experiment (FORTE) model is used here (Sinha and Smith 2002; Smith 2004); a coupled oceanatmosphere model composed of two separate GCMs. The ocean component is the Modular Ocean Model Array (MOMA) version (Webb 1996), a variant of the widely distributed the Modular Ocean Model (MOM), based on the Geophysical Fluid Dynamics Laboratory (GFDL) code (Pacanowski et al. 1991). Our version uses an implementation of the Ocean Circulation and Climate Advanced Modeling Project (OCCAM) free surface scheme (Webb et al. 1998). Mixing can be done along Cartesian axes or using the isopycnic scheme of Gent and McWilliams (1990) and Gent et al. (1995) (i.e., GM mixing). A simple energy conserving sea ice parameterization has been implemented to insulate the polar oceans from subzero temperatures. The atmosphere is the Reading Intermediate General Circulation Model (IGCM3) spectral model (Forster et al. $2000)$, in sigma $(\sigma)$ vertical coordinates, derived from the dynamical core of Hoskins and Simmons (1975). It has a multiband radiation scheme including effects of water, carbon dioxide, and ozone, and uses a convective adjustment scheme based on Betts (1986). The cloud scheme is a simplified version of that detailed in Slingo (1987), and has four distinct cloud variables. The cloud fraction of three of these types is based on exceeding a 
critical value of relative humidity, at either low $(\sigma>$ $0.7)$, middle $(0.35<\sigma<0.7)$ or high $(\sigma<0.35)$ altitudes, while the fourth, deep convective cloud, is parameterized from precipitation rates. A further class, shallow convective cloud, is set to a low constant value based on climatology. The model includes a land surface scheme able to hold moisture and track soil temperature; surfaces are assigned a vegetation index that determines roughness length and albedo. Ocean and atmosphere components are coupled together using the Ocean Atmosphere Sea Ice Soil (OASIS) coupler (Terray et al. 1999) with a land-tiling scheme to correctly match the differing grids to each other and conserve energy. Wind stresses, heat and freshwater fluxes, and the sea surface temperature are exchanged at the beginning of every model day.

To achieve the long integration times required to reach equilibrium, the model has been used at a rather coarse resolution $\left(4^{\circ} \times 4^{\circ} \times 15\right.$ vertical levels in the ocean, T21L22 for the atmosphere). The computationally cheaper Cartesian mixing scheme is used in the ocean, rather than the isopycnic one, with a vertical diffusivity of $1 \mathrm{~cm}^{2} \mathrm{~s}^{-1}$. This value is set as the basin average following Munk and Wunsch (1998) and is of an order common to low-resolution ocean models, although substantially higher than those measured in the ocean, away from boundaries. Initial integrations of this version of the model show that, while its resolution means that the simulation of current climate contains significant deviations from observations (see the appendix), the model does come to its own, stable equilibrium without the use of flux adjustments. This is obviously essential when trying to simulate climates for which no observations exist. FORTE's basic representation of current climate does contain many features recognizable from observations and allows us some confidence in applying the model to more qualitative questions in theoretical climate situations.

\section{Experimental setup}

There are three variations on the basic aquaplanet setup, designed to cover a (highly idealized) spectrum of ocean circulation regimes. Each case differs from the others only by a low area of land that stretches the whole depth of the ocean, blocking ocean flow completely but presenting no physical obstruction to the overlying atmosphere. Coupled aquaplanet integrations are not a common feature of the literature, so all of the following experiments have the potential to produce some interesting dynamics.

The first case, "WaterWorld" (Fig. 1a), is the simplest possible example of a coupled ocean-atmosphere

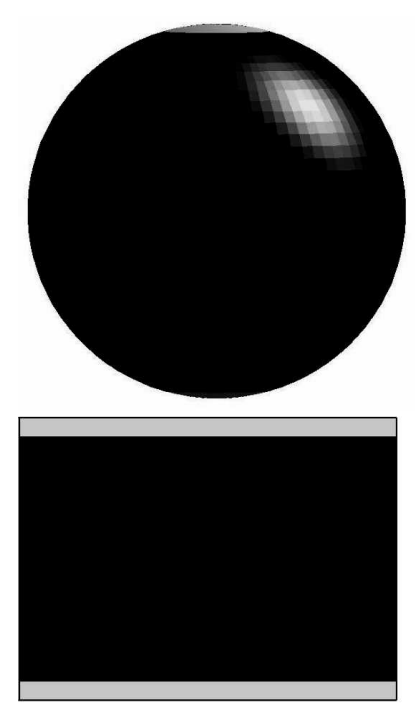

(a)
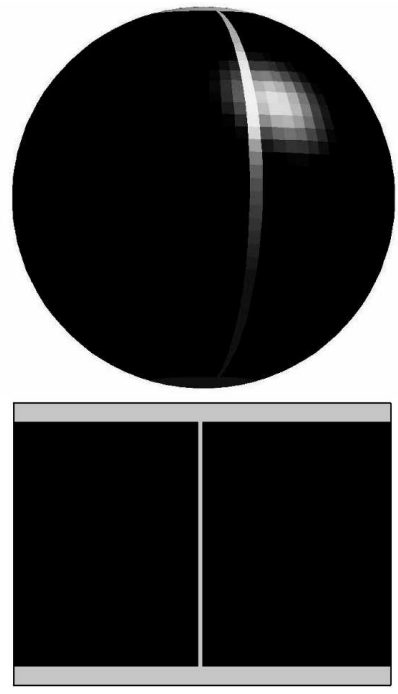

(b)

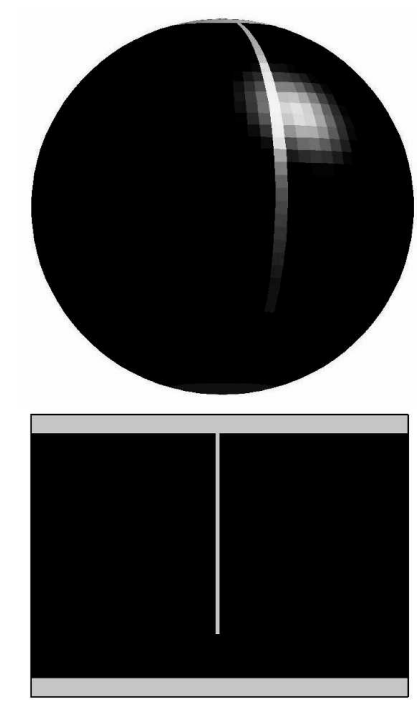

(c)

FIG. 1. Aquaplanet geographies: (a) WaterWorld, (b) RidgeWorld, and (c) DrakeWorld.

system. It lacks any form of barrier to zonal flow in the ocean, so is unable to support any form of zonally integrated meridional flow by geostrophy. It is not, however, a pure aquaplanet, as there are islands over the poles (stretching down to $78^{\circ}$ ) to reduce time-stepping constraints caused by grid convergence. All the experiments feature these polar islands.

The second scenario, "RidgeWorld" (Fig. 1b), represents a single closed ocean basin that can support a normal Sverdrup circulation. The flow forms in such basins have been extensively studied in models ranging from the analytic to eddy resolving; many aspects are 


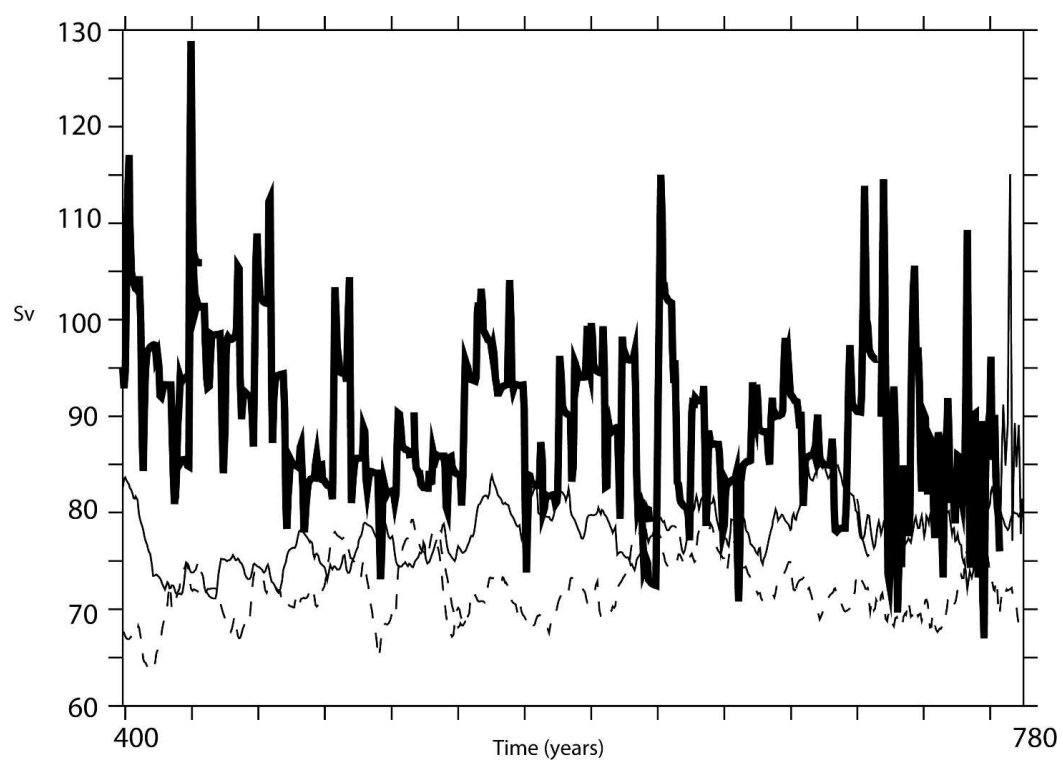

FIG. 2. Twice-yearly average of the maximum strength of the oceanic meridional overturning streamfunction (Sv) for the last $300 \mathrm{yr}$ of the climate spinups, the first 200 of which are integrated with periodic coupling scheme: WaterWorld (light, solid line); RidgeWorld (heavy, solid line); and (dashed line) DrakeWorld.

well understood, but the more general coupled aquaplanet setting of this scenario here is novel.

The third scenario, "DrakeWorld" (Fig. 1c), is named after the gap between South America and Antarctica that is the narrowest restriction to circumpolar flow in today's Southern Ocean. It can support geostrophic gradients and closed basin flow in the landed Northern Hemisphere, but a gap in the barrier in the Southern Hemisphere allows for circumglobal flow, a kind of idealized Antarctic Circumpolar Current (ACC). The dimensions of the gap here are rather different from those of the real Drake Passage, being much wider, farther south, and not forming a sill. Our intention is not to conduct an idealized Drake Passage experiment, but just to make a simple linear combination of the previous two scenarios for the purposes of an abstract experiment.

In all the experiments both land surface and seafloor are flat, with the land at a constant 50-m height. All land surface points are set to a constant albedo value of 0.24 . Any moisture that overflows the bucket scheme of the land surface is instantly moved to the nearest ocean grid point. Orbital parameters and levels of $\mathrm{CO}_{2}$ are kept at modern-day values.

The components are first spun up separately with the WaterWorld geography, forced with sea surface temperature (SST), salinity, and wind profiles obtained from a short coupled run, and then coupled together and integrated for a further $500 \mathrm{yr}$. All experiments are initialized from this state and run for a further $800 \mathrm{yr}$. The periodically synchronous time-stepping scheme of Sausen and Voss (1996) is used to maximize computational efficiency during the coupled spinup of each experiment; tests within the course of this study have shown that this method is able to reliably produce the same final states as fully synchronous integrations. The last $100 \mathrm{yr}$ of each experiment are conducted with fully synchronous time stepping to remove any frequency artifacts from the data sampled. Unless otherwise stated, all results presented here are from climatologies produced by averaging over the last $30 \mathrm{yr}$ of this synchronous period.

At the end of the experiments presented here there are small temperature drifts of $0.03^{\circ}-0.09^{\circ} \mathrm{C}$ century ${ }^{-1}$ in the deep ocean. However, there is no significant drift in the maximum MOC strength (Fig. 2) or in characteristics (temperatures, rainfall patterns, etc.) of the surface climate, so the resulting climates will be analyzed as steady states of their respective configurations.

\section{WaterWorld climate}

An overview of the WaterWorld climate will be presented here, both as a background on which to base comparisons with the other runs and on its own merits. The "modern reference" used is presented in the appendix: a nonflux-adjusted coupled run of the model at the same resolution with a modern geography. 


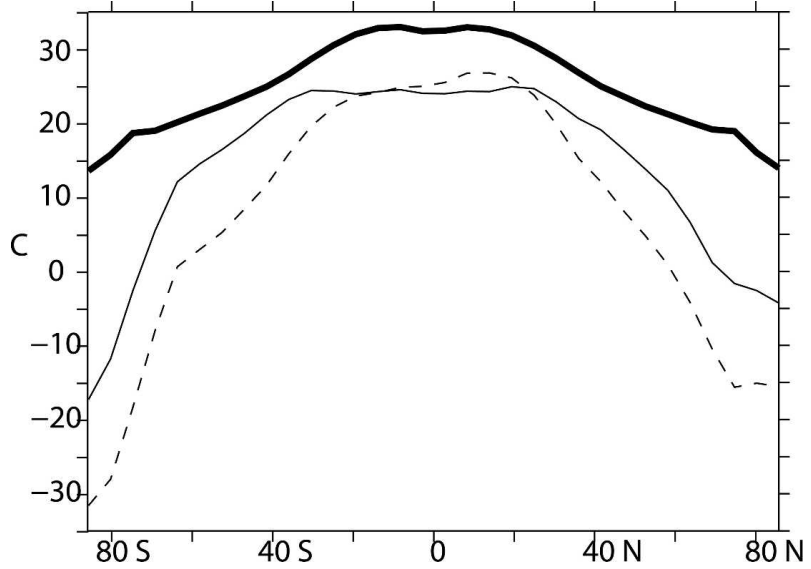

FIG. 3. Annual zonal average air surface temperature $\left({ }^{\circ} \mathrm{C}\right)$ for WaterWorld (heavy), modern reference (light), IGCM3 forced by climatology (dashed).

\section{a. Atmosphere}

The WaterWorld climate is significantly warmer than that observed for the modern reference (Fig. 3). The annual average air surface temperature is $27.5^{\circ} \mathrm{C}$, with a shallow equator-to-pole temperature gradient from $33^{\circ} \mathrm{C}$ in the Tropics to $13^{\circ} \mathrm{C}$ over the polar islands. Only small areas drop below freezing in winter, and those are over the polar islands-there is no sea ice formed at any time of year. The lack of zonal orographic barriers in either ocean or atmosphere means that the distributions of the various fields are almost perfectly zonal. A small degree of hemispherical asymmetry remains from the eccentricity of the earth's orbit, which provides slightly more insolation during Northern Hemisphere winter than the Southern Hemisphere winter.

The rainfall distribution is equally zonal, and, al-

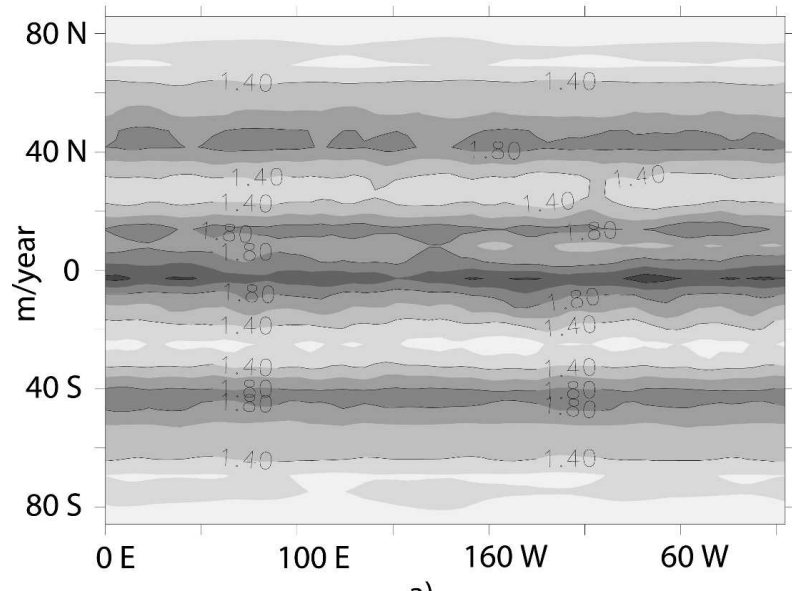

a)

FIG. 4. (a) Annual average precipitation $\left(\mathrm{m} \mathrm{yr}^{-1}\right)$ for WaterWorld and (b) annual, zonal average cloud fractions-low cloud (solid), convective cloud (dashed) for WaterWorld (heavy) and modern reference (light). though lacking in localized maxima and minima, at 1.57 $\mathrm{m} \mathrm{yr}^{-1}$ the global average is $23 \%$ higher than that of the modern reference (Fig. 4a). Levels of humidity in the WaterWorld atmosphere are also increased, and there is a significant increase in the amount of low cloud (i.e., the cloud located in the lowest third of the atmosphere, in pressure terms). An increase in convective cloud reflects the strengthening of the atmospheric overturning circulation (Fig. 4b). The seasonal position of the rainfall bands follows that of the upwelling regions of the vertical overturning in the atmosphere.

Surface winds speeds are little reduced compared to those simulated for modern climate, despite the much reduced meridional temperature gradient (Fig. 5). This is likely due to the reduced surface friction from the removal of the land. Higher up, the jet streams (not shown) are little changed in position or strength from those found in the current climate simulation as the shallow meridional temperature gradient at the surface steepens at higher altitudes.

The warmth of the WaterWorld climate can be usefully analyzed through the application of a simple analytic energy balance model, fitting certain radiative parameters to the top and bottom of atmosphere fluxes obtained. The model is constructed as follows (see Fig. 6 for a schematic).

The planetary albedo, $\alpha_{p}$, which is characteristic of the system as a whole, is derived from the diagnostics as the globally averaged amount of shortwave that escapes from the top of the atmosphere (TOA), $\mathrm{SW}_{\mathrm{up}}^{\mathrm{TOA}}$, divided by the incident solar shortwave, $\mathrm{SW}_{\mathrm{down}}^{\mathrm{TOA}}$.

$$
\alpha_{p}=\frac{\mathrm{SW}_{\mathrm{up}}^{\mathrm{TOA}}}{\mathrm{SW}_{\mathrm{down}}^{\mathrm{TOA}}} .
$$

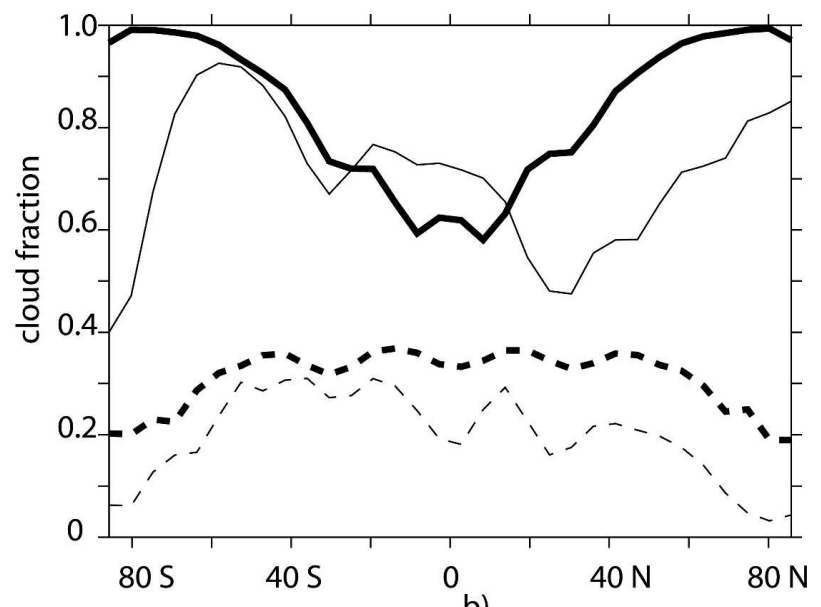

b) 


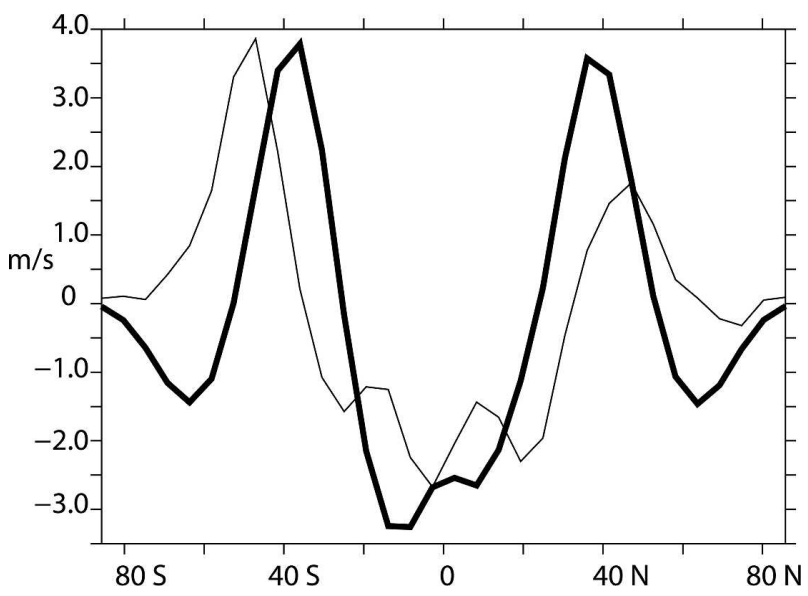

FIG. 5. Annual, zonal average zonal surface winds for WaterWorld (heavy) and modern reference (light).

The $\mathrm{SW}_{\mathrm{up}}^{\mathrm{TOA}}$ is then deconstructed into its dependence on three different parameters: the shortwave reflectance of the atmosphere, $\alpha_{a}$; the shortwave transmissivity of the atmosphere, $\varepsilon_{S}$; and the shortwave reflectance of the earth, $\alpha_{e}$, where

$$
\begin{gathered}
\alpha_{e}=\frac{\mathrm{SW}_{\mathrm{up}}^{\mathrm{BOA}}}{\mathrm{SW}_{\mathrm{down}}^{\mathrm{BOA}},} \\
\mathrm{SW}_{\mathrm{up}}^{\mathrm{TOA}} \sim \varepsilon_{S} \cdot \mathrm{SW}_{\mathrm{up}}^{\mathrm{BOA}}+\alpha_{a} \cdot \mathrm{SW}_{\text {down }}^{\mathrm{TOA}},
\end{gathered}
$$

and

$$
\mathrm{SW}_{\text {down }}^{\mathrm{BOA}} \sim \mathrm{SW}_{\text {down }}^{\mathrm{TOA}} \cdot\left(\varepsilon_{S}-\alpha_{a}\right),
$$

where $\mathrm{SW}_{\text {down }}^{\mathrm{BOA}}$ is the amount of shortwave incident on the earth's surface, and $\mathrm{SW}_{\mathrm{up}}^{\mathrm{BOA}}$ is the amount reflected from the surface.

These last two are approximated from assuming that reflectance and absorption both happen independently throughout the entire depth of the atmosphere.

The longwave transmissivity is taken as

$$
\varepsilon_{L}=\frac{\mathrm{LW}_{\mathrm{up}}^{\mathrm{TOA}}}{\mathrm{LW}_{\mathrm{up}}^{\mathrm{BOA}}},
$$

where $\mathrm{LW}_{\text {up }}^{\mathrm{BOA}}$ is the globally averaged amount of longwave radiation emitted by the earth's surface and $\mathrm{LW}_{\mathrm{up}}^{\mathrm{TOA}}$ is the amount of TOA longwave radiation.

Solving Eqs. (1)-(5) for the WaterWorld climate, diagnosing the long and shortwave fluxes at the top and bottom of the atmosphere, as well as the surface albedo from the model, gives results as for Table 1 .

This shows a planet with the same shortwave response to solar insolation as the modern reference, even though the surface albedo has been significantly reduced by the removal of the continental landmasses. This is due to the increase in low cloud fraction, which increases the reflectivity of the atmosphere and produces a planetary albedo for the combined system that is the same as that of the modern reference. The longwave radiation budget is, however, substantially different from that of the reference climate, with an increase in the amount of longwave radiation absorbed in the atmosphere (Table 1); this is due to the increased water vapor content of the WaterWorld atmosphere, which

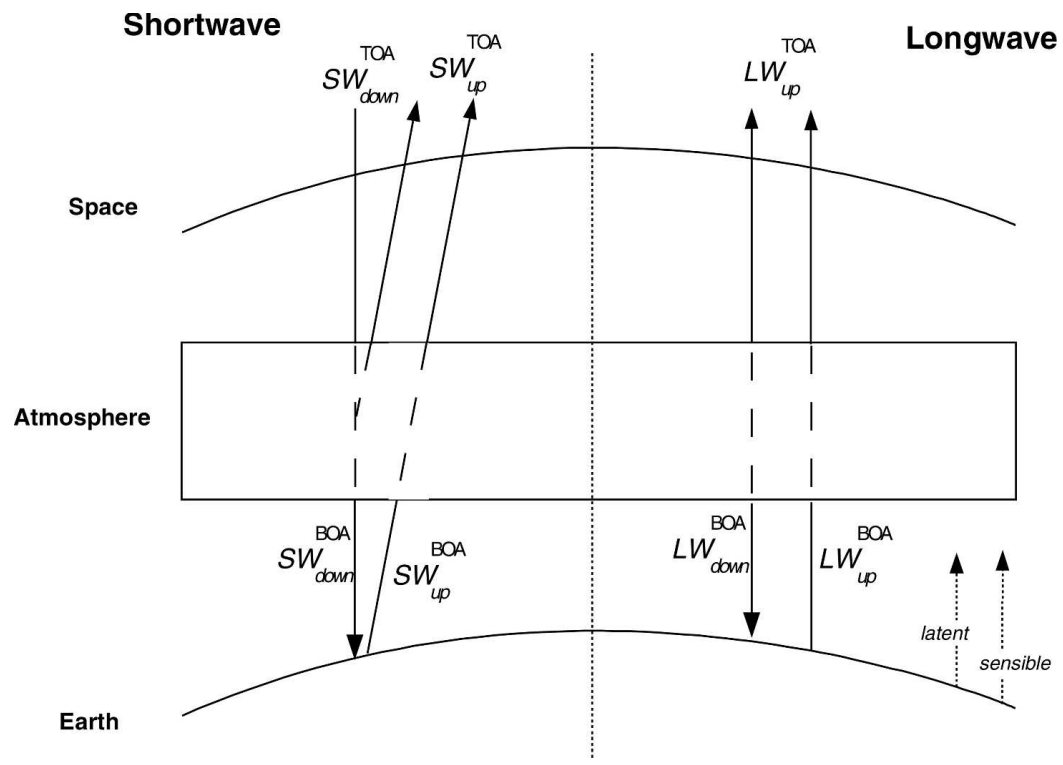

FIG. 6. Schematic of the various terms in the simple radiative model [see Eqs.

(1)-(5)]. 
TABLE 1. Comparison of parameters for the modern reference and WaterWorld (WW) for the simple radiative model [Eqs. (1)(5)] $\alpha_{p}$ : planetary albedo; $\alpha_{a}$ : atmospheric albedo; $\varepsilon_{S}$ : shortwave transmissivity of atmosphere; $\alpha_{e}$ : surface albedo; $\varepsilon_{L}$ : longwave transmissivity.

\begin{tabular}{lccccc}
\hline \hline & $\alpha_{p}$ & $\alpha_{a}$ & $\varepsilon_{S}$ & $\alpha_{e}$ & $\varepsilon_{L}$ \\
\hline RealWorld & 0.314 & 0.251 & 0.802 & 0.14 & 0.556 \\
WW coupled & 0.315 & 0.275 & 0.774 & 0.10 & 0.509 \\
\hline
\end{tabular}

strengthens the greenhouse effect (Fig. 7a). Although the reduction in surface albedo does not play a role in maintaining the energy balance that keeps WaterWorld warmer, it is most likely an important trigger for the change of state. The lowered surface albedo from the removal of the land causes an initial warming that increases the water vapor content of the atmosphere and strengthens greenhouse warming. Combined with the increase in availability of water as the configuration changes from separated basins to a global ocean, this process can occur uniformly over the entire globe, leading to a particularly strong greenhouse. Further climate feedbacks then result, like the global buildup of reflective cloud that eventually counteracts the surface albedo change in the shortwave budget.

The longwave absorption profile shown in Fig. 7b also shows that much of the increased greenhouse is effective at higher latitudes, poleward of $40^{\circ}$. Global warming also results in a loss of ice and snow, affecting the surface albedo at high latitudes (also shown in Fig. $7 b$ ). These factors provide a significant radiative warming at high latitudes, and it is this warming that is primarily responsible for the drastic reduction in meridi- onal surface temperature gradient. Comparing the meridional energy transports of the WaterWorld and reference systems (Fig. 8) shows no significant increase in either ocean or total system transport to the poles; the main feature seen here is a return to a hemispherically symmetric energy transport from the Northern Hemisphere biased curve seen for the modern reference.

That the total system transport for WaterWorld is so similar to that of the modern reference is surprising, given the significant changes in radiative balance at high latitudes. Energy transports in the system can be seen as a response to the latitudinally dependent radiative forcing; if the radiative forcing has changed to reduce the gradient, then less meridional transport should be required to keep the system in equilibrium. However, the discussion of changes in radiative forcing has been of the changes in TOA radiative fluxes relative to those at the bottom. In this case, while the fluxes at the bottom have changed significantly, those at the top have not, as the warming signal is not uniform with altitude. The absorption and reflection ratios considered thus show considerable change, while the TOA fluxes (and thus the total energy transport) remain the same. That the temperature gradient aloft on WaterWorld closely resembles that of the modern reference suggests that the high-latitude lapse rate on WaterWorld has increased. This can also be traced back to the increased water vapor content of the high-latitude atmosphere, which decreases the stability of the air column: latent heat released in the condensation of the water vapor increases the buoyancy of rising air parcels.

The constancy of the total system transport seen here

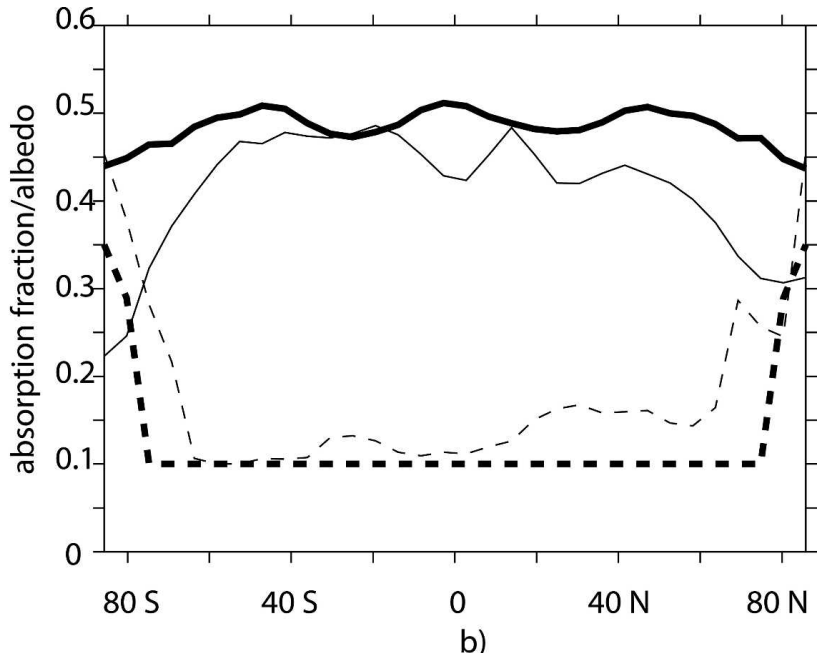

b)

FIG. 7. (a) Specific humidity vs height and (b) longwave absorption fraction (solid) and surface albedo (dashed) for the WaterWorld (heavy) and modern reference (light) atmospheres. 


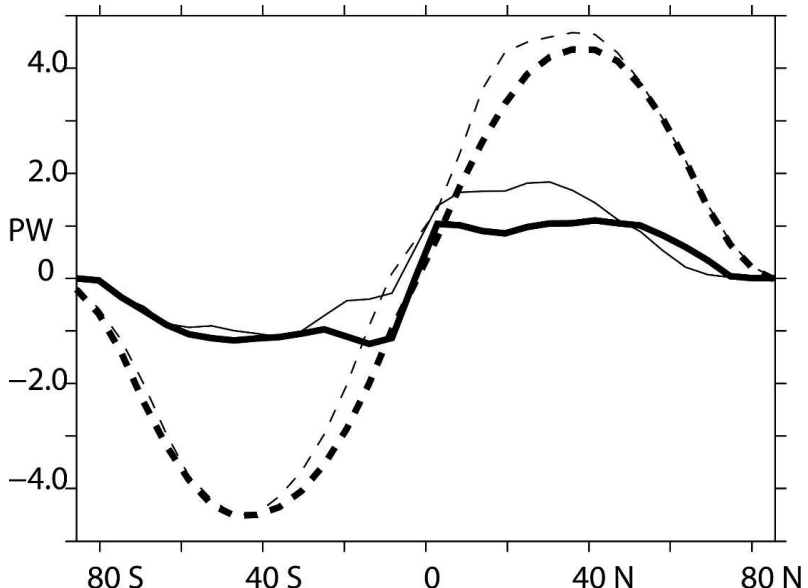

FIG. 8. Ocean (solid) and total (dashed) energy transports for WaterWorld (heavy) and the modern reference (light).

is consistent with the suggestion, initially proposed by Bjerknes (1964) and since supported by many subsequent studies (e.g., Manabe et al. 1975; Clement and Seager 1999; Winton 2003), that the sum of the ocean and atmosphere meridional energy transports remains generally constant throughout any changes forced in the system. Stone (1978) provided a theoretical basis for this result, contending, from some basic considerations, that the controlling factors on the strength and form of this transport are limited to the size, rotation rate and axis tilt of the earth, the solar constant, and the mean hemispheric albedo. These basic physical parameters of the aquaplanet globe here are unchanged, including the planetary albedo, although the constancy of this albedo results from internal changes within the climate system and is not an external parameter. Stone (1978) suggested that his analysis ought to hold even for unusual scenarios with no ice cover, or even no ocean at all, so the coupled system here lends support to this theory under a quite extreme setup.

\section{b. Ocean circulation}

On WaterWorld, the zonal nature of the surface wind field and the lack of orographic boundaries means that surface currents are largely zonal, and a global, winddriven zonal current results whose spinup is limited by friction within the ocean and at the bottom. Surface currents reach up to $1 \mathrm{~m} \mathrm{~s}^{-1}$ in the Tropics (Fig. 9). The wind-driven flow here may be slightly overestimated, as surface ocean velocities are not taken into account when calculating the wind stress in the atmosphere (Pacanowski 1987; Jungclaus et al. 2006).

As with the temperature field, the sea surface salinity is very zonally even (Fig. 10). Despite a generally in-

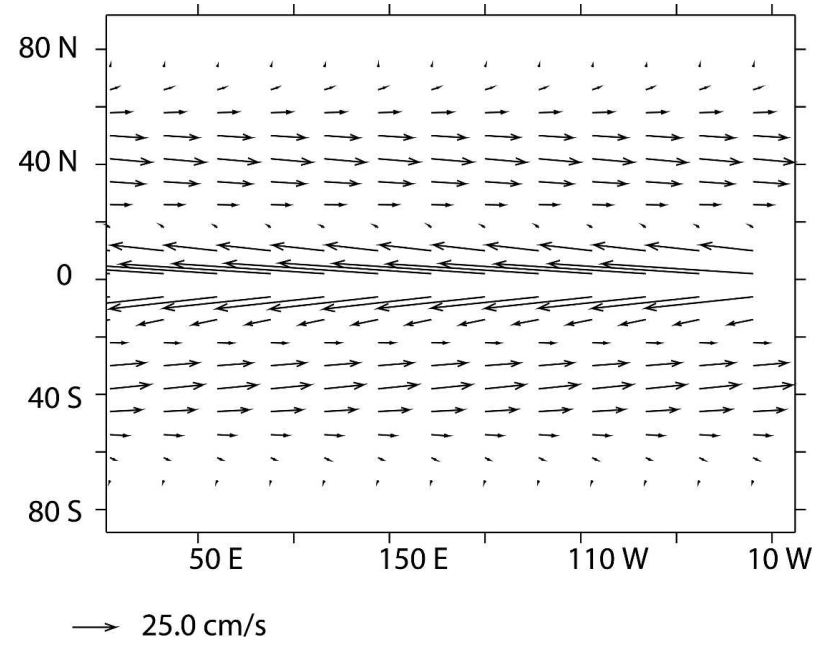

FIG. 9. Annual average sea surface currents $\left(\mathrm{cm} \mathrm{s}^{-1}\right)$ for WaterWorld.

creased hydrological cycle, there is less latitudinal variation than in the modern fields. This is due to a number of factors, including locally compensating changes in evaporation and precipitation, a larger ocean surface area, and significant diffusive mixing (this will be addressed later). As will be seen, changes in the hydrological cycle actually have little influence on the ocean circulations in these scenarios, and thus little part to play in determining the transports or climate feedbacks in the system.

The MOC (Fig. 11a) consists of deep Ekman cells that stretch down almost to the ocean floor. In assessing why these cells are so much deeper than the surface layer Ekman cells seen in the ocean basins today, it is



Fig. 10. Annual, zonal average sea surface salinity (psu) for WaterWorld (heavy), the modern reference (light), and an observed climatology (dashed). 


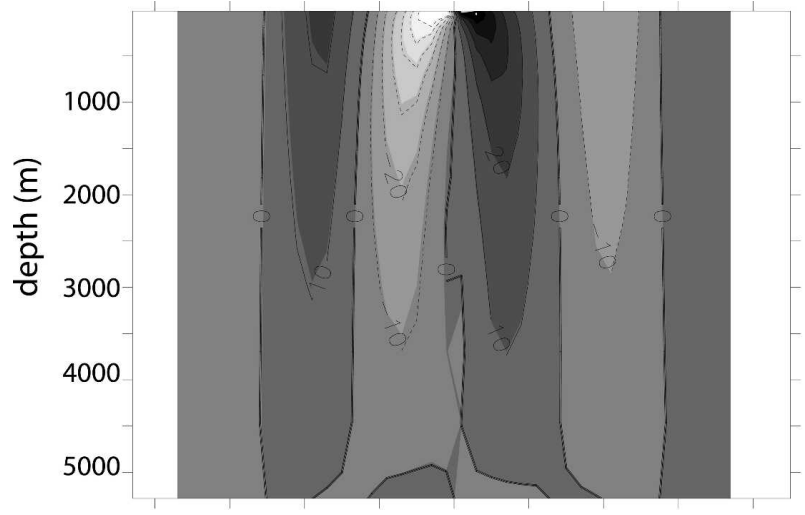

a)

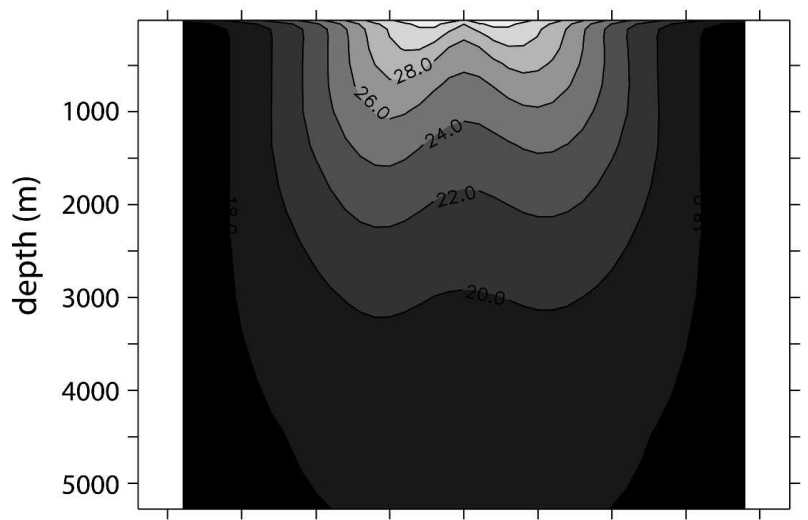

b)



FIG. 11. Waterworld (a) meridional overturning streamfunction (Sv, positive clockwise); (b) zonally, annually averaged temperature $\left({ }^{\circ} \mathrm{C}\right)$ vs depth; and (c) ocean heat transport components (PW), advective (light), nonadvective (dashed), and total (heavy).

useful to consider the force balance in action. The lack of zonal pressure gradients on WaterWorld means that mean meridional flow is no longer controlled by geostrophy-in an inviscid fluid, the forces that would be left to balance each other are the zonal wind stress and bottom friction. This situation, in the context of the
ACC, has been often addressed in the literature (e.g., Gill and Bryan 1971; Cox 1989; Marotzke and Willebrand 1991). Here, the finite resolution of the model requires a certain amount of artificial viscosity for stability reasons, and this allows for the return flow to occur at all depths. The actual pattern seen here is reproduced well by a simple model where the meridional flow of the surface layer $(30 \mathrm{~m})$ of the model, forced only by the zonal wind stress, is compensated by a barotropic return flow.

The shallow meridional surface temperature gradient in the atmosphere, coupled with the wind-forced vertical motion present at nearly all latitudes leads to an ocean that is rather weakly stratified, without a sharp thermocline (Fig. 11b). The rather high overturning rate at the surface of the wind-driven cells is largely due to the global scale of the basin over which the velocities have been integrated.

The heat transport due to this overturning circulation is very different from that seen in the global ocean today. In the tropical cells, water forced poleward at the surface is compensated for by cooler equatorward flow at depth, producing a poleward heat transport. However, the divergence of the surface wind field means that the subtropical cells rotate in the opposite sense to the tropical ones, moving warmer surface water equatorward to provide an equatorward heat transport (Fig. 11c).

Diagnosing the total OHT from the divergence of the surface heat fluxes produces a rather different pattern however, with poleward OHT at all latitudes. The reason for this difference is that the OHT here has a very large nonadvective part, which largely opposes the advective transport. In the Tropics, where the advective transport is poleward, vigorous upwelling of cooler deep water at the equator provides a temperature gradient for equatorward heat diffusion, reducing the advective heat transport. In the subtropics, where SSTs cool toward the high latitudes, downgradient diffusion acts in the opposite direction to the equatorward advective transport, this time outweighing it to cancel the advective transport and provide an overall poleward OHT. There are analogies here with both the modern ACC, where eddies are an important meridional transport process, and with the atmosphere, similarly lacking in zonal boundaries for most of its depth, where the majority of the poleward heat transport in the midlatitudes is carried by eddies rather than the mean circulation. Although partly present for numerical reasons, horizontal diffusion in the ocean model is also used as a cheap parameterization of the effect of eddies, and the diffusive transport here seems to be playing the same role. 



FIG. 12. Zonal, annual average SST $\left({ }^{\circ} \mathrm{C}\right)$ on changing from Cartesian to GM mixing for the WaterWorld scenario. (a) Time vs latitude (the switch is made at year "0" here), (b) SST before switch (solid) and after $250 \mathrm{yr}$ of GM run (dashed) GM mixing for the WaterWorld scenario.

The purely horizontal-vertical mixing used in this version of the model provides an undoubtedly flawed representation of eddies and mixing in the real ocean, with areas of sloping isopycnals seeing erroneously high diapycnal flux, and the scheme is only used here for reasons of computational affordability. There is a clear similarity between the aquaplanet here and the physical conditions in the Southern Ocean in the real world, where the eddy contributions to both tracer and momentum transports are of major importance-how then can a Cartesian mixing scheme and the high horizontal diffusive transport it produces provide believable results in this context? To assess the degree of error involved in the use of the affordable Cartesian mixing, a 250-yr run of the WaterWorld scenario using GM isopycnal mixing was conducted. Although this is not long enough for a new thermal equilibrium to be established throughout the ocean, it should be long enough to see whether the system is drifting toward a substantially different state, particularly in this case where, as will be seen later, a significant reduction in WaterWorld OHT rapidly feeds back through the coupled system to produce a very different climate.

The introduction of GM mixing does reduce the degree of diapycnal mixing in the WaterWorld ocean, allowing the surface layer to warm slightly. There is a rapid increase in global average SST of just over a degree, which then slowly reduces again, although staying above the previous global average. This warming occurs initially at low latitudes, but by the end of this run, tropical SSTs are as before, and there has been a warming of just over a degree around $30^{\circ}$ and cooling of just over a degree at the poles, sharpening the meridional temperature gradient somewhat (Fig. 12). There is no change in the seasonal variance of the SST and there is still no sea ice formed at any time. The MOC pattern observed is much the same, with a slightly deeper penetration of the Ekman cells, probably due to an increase in wind speeds caused by the small increase in the surface temperature gradient. The OHT picture is also much the same as for the case with Cartesian mixing, if a little stronger due to the increase in the MOC mass transport. Here, the diffusive component of the Cartesian picture is replaced by an eddy heat flux of very similar form and magnitude. Although there are differences between the two models, there do not appear to be any qualitative changes in the climate, at least on the time scales run here. Although a poor one, diffusive transport in a low-resolution model such as this is meant as a parameterization of eddy transport, and in this case it appears to produce an acceptable approximation to the state produced by the more sophisticated GM parameterization.

\section{Swamp WaterWorld}

To assess the role of the OHT in the WaterWorld climate, the steady state is integrated further with all ocean transports and velocities switched off, reducing the ocean part of the coupled model to a 30-m-deep swamp ocean. The ocean is thus able to store and release heat and water locally but not transport it, either by advection or diffusion. Shutting off the ocean transport in this scenario produces significant climatic effects: most obviously a global surface cooling of $8^{\circ} \mathrm{C}$. The cooling is more pronounced at the poles, causing a 


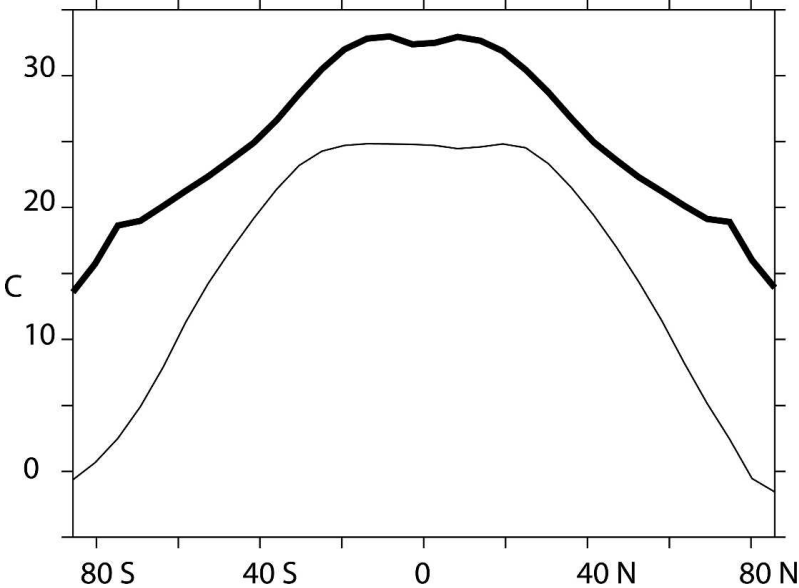

FIG. 13. Zonal, annual average surface air temperature profiles for WaterWorld (heavy) and the swamp WaterWorld (light).

slight sharpening of the equator-to-pole temperature contrast (Fig. 13). The change in global climate clearly shows that there is a substantial interaction with the atmosphere that leads to a change in the global mean radiative properties of the system.

Assessing the new fluxes derived from the OAGCM with the analytic model [Eqs. (1)-(5)] helps to analyze what has happened (Table 2). Although the surface albedo is unchanged, the planetary albedo has gone up, showing that the system is not absorbing as much of the incoming solar radiation as before. In addition to this, the longwave absorption of the system has been reduced, and with it, its ability to retain the heat it does have.

These radiative changes can be attributed to climate variables in the system. The increase in the TOA upward shortwave radiation, most notably over the Tropics, is collocated with a large increase in low-level clouds (Fig. 14). Similarly, the global reduction in longwave absorption can be attributed to a general reduction in the water content of the atmosphere. How are these changes linked to the change in OHT?

In the absence of other feedbacks, the reaction expected from the inhibition of a poleward OHT would be a reduction in high-latitude temperatures and an increase in tropical ones. Looking closely at the initial temperature trends as OHT is cut off, this is indeed what happens for the first 60 days. However, the rise in

TABle 2. Same as in Table 1, but for WW, coupled and swamp.

\begin{tabular}{lccccc}
\hline \hline & $\alpha_{p}$ & $\alpha_{a}$ & $\varepsilon_{S}$ & $\alpha_{e}$ & $\varepsilon_{L}$ \\
\hline WW coupled & 0.315 & 0.275 & 0.774 & 0.10 & 0.509 \\
WW swamp & 0.342 & 0.302 & 0.790 & 0.10 & 0.541 \\
\hline
\end{tabular}

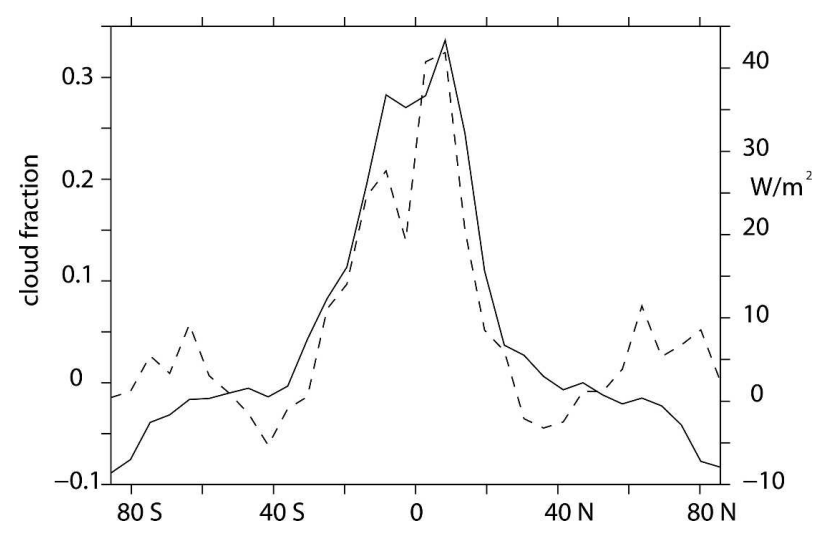

FIG. 14. Differences in outgoing shortwave radiation (positive upward, dashed, right axis) and low cloud increase (solid, left axis) between the swamp and normal WaterWorld experiments (swamp - normal).

tropical temperatures is not as large as the high-latitude decrease and after around 60 days the tropical temperatures fall, too (Fig. 15). The increase in tropical lowlevel clouds (the only cloud type to show significant increase in the region of the increase in shortwave reflectivity) precedes the tropical temperature decrease.

These results are echoed in a number of studies (Winton 2003; Clement and Seager 1999; Herweijer et al. 2005) that conclude that an active OHT warms the global mean climate. They also found feedbacks with low-level marine clouds and atmospheric water vapor, although the extreme case here does produce rather more drastic results. The fact that the increased cloud levels persist past the reduction in tropical SST may be

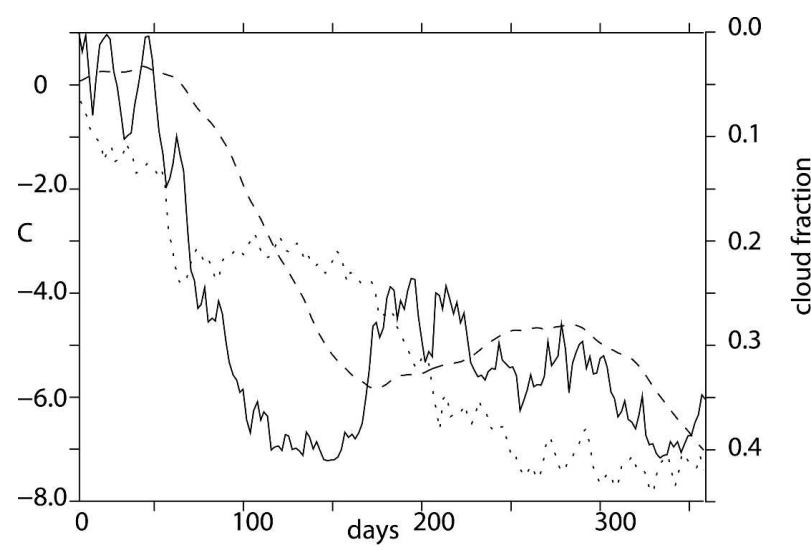

FIG. 15. Evolution of low-latitude $\left(5^{\circ} \mathrm{S}-5^{\circ} \mathrm{N}\right)$ temperature (dashed, left axis), high-latitude $\left(60^{\circ}-70^{\circ} \mathrm{N}-\mathrm{S}\right)$ temperature (dotted, left axis) and tropical low cloud cover (solid, right axis) for swamp WaterWorld. Data are averaged from the relevant latitude band in both hemispheres and then subtracted from the behavior observed for the scenario with a fully dynamic ocean for the same year. 
connected to observations (Klein and Hartmann 1993) that lowered SSTs are correlated with increased lower atmosphere stability and the strength of the 700-mbar inversion. An alternative explanation could lie in that the increased temperature gradient from the lack of OHT will lead to enhanced mixing of the warm, more humid tropical air with the cooled, dryer air poleward, producing more clouds.

Herweijer et al. (2005) identified a "dynamic" water vapor feedback, where the inclusion of OHT led to an increase of surface temperature, but a decrease in outgoing TOA longwave radiation. This cannot happen with a purely locally caused increase in water vapor, and shows where dynamical changes in the atmospheric circulation, forced by the changing OHT, are partly responsible for the change in temperature. For WaterWorld, this occurs over the equator, and to a small degree in the areas between $40^{\circ}$ and $60^{\circ} \mathrm{N}-\mathrm{S}$; surface temperature increases of up to $5^{\circ} \mathrm{C}$ occur with the same or less TOA outgoing longwave when the OHT is active. In the equator, we can appeal to changes in the mean Hadley cell circulation as outlined in Herweijer et al. (2005), but in the midlatitudes the signal is rather small and difficult to attribute to any single cause. It may be linked to a small amplification of the mean overturning circulation in the coupled case, or may not in fact be a dynamic case and just due to a particularly strong local increase in greenhouse trapping. Shutting down the OHT does cause a general increase in the atmospheric energy transport (AET) - it is unchanged only between $10^{\circ}$ and $30^{\circ}$-but the increase does not entirely compensate for the loss of OHT, and the total energy transport is reduced by up to $1 \mathrm{PW}$ equatorward of $50^{\circ}$. Since the planetary albedo has now changed, the Stone (1978) argument as to the constancy of OHT + AET given certain unchanged parameters is not strictly refuted here, although in experiments cited by Stone (1978) involving the GFDL model the removal of the ocean did not change either the planetary albedo or the total transport.

A comparison against the modern reference shows that the high latitudes of the coupled WaterWorld warm far more than the Tropics. Moreover, the tropical warming initially seen in the swamp WaterWorld as the OHT is inhibited is small. These both point to some form of cap on low-latitude SSTs, such as has been suggested for the real climate system (Pierrehumbert 1995; Ramanathan and Collins 1991). The "radiator fin" concept of Pierrehumbert (1995) suggests that excess heat is transported to higher latitudes where the overlying atmosphere is not saturated with water vapor and thus has "windows" through which heat can be radiated. This applies to the coupled WaterWorld,

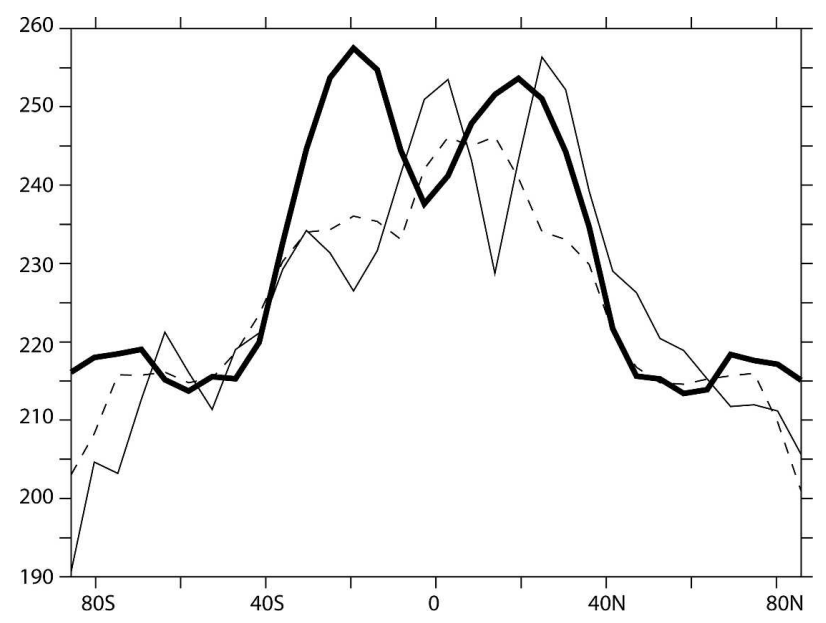

FIG. 16. The TOA outgoing longwave flux. Coupled WaterWorld (solid, heavy), swamp WaterWorld (dashed, heavy), and modern reference (light).

where strong spikes in the TOA outgoing longwave for the coupled WaterWorld can be seen, centered on $20^{\circ} \mathrm{N}-\mathrm{S}$ (Fig. 16). Although the swamp WaterWorld has no OHT and the spikes in TOA outgoing longwave are reduced, there is some increase in tropical AET (but not enough to fully compensate the change in OHT) as the ocean is switched off, suggesting that the mechanism is also acting to some degree in this scenario as well. Cloud albedo feedbacks must also play an important role for the coupled case, although not via convective cloud, which might be expected to respond to increased tropical SSTs but in fact changes little. Instead, changes in low cloud fraction that reflect the incoming shortwave have a significant effect. For the swamp WaterWorld, the radiator fin mechanism is seen to be much reduced. Despite the loss of these fins though, tropical SSTs do not increase substantially, and a strong increase in low clouds is seen. This suggests that cloud feedbacks are the dominant mechanism in this case, although the large changes occurring at higher latitudes may override the local effects in the Tropics. The significant climatic changes that occur almost immediately on WaterWorld following the inhibition of OHT in this case also lend some confidence to the conclusions from the short GM mixing run before: the model here reacts rapidly to a change in OHT via feedbacks through the whole climate system, whereas in the GM-enabled run no such changes occur within a century. The GMenabled model thus appears to produce qualitatively the same transports as for the simpler, Cartesian mixing model in this scenario, and the use of the more sophisticated mixing parameterization does not qualitatively change the climate state obtained. 


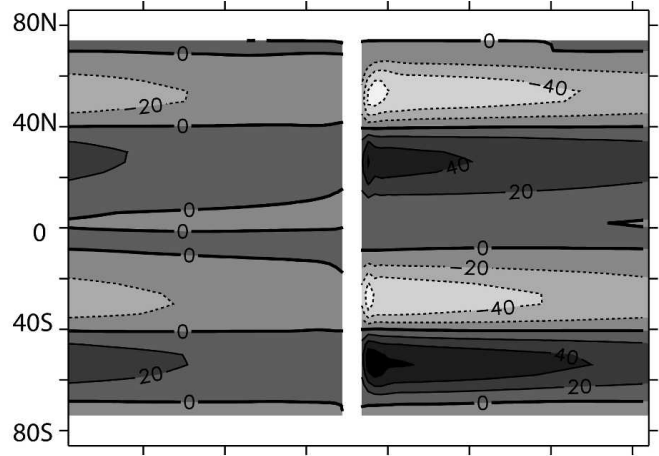

a)

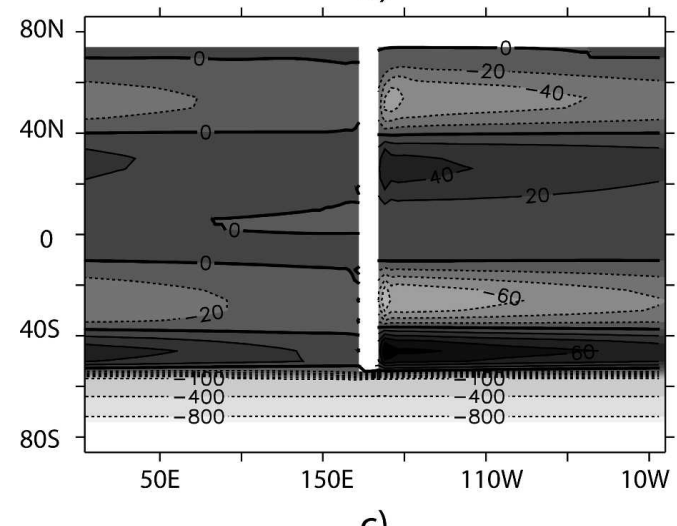

c)

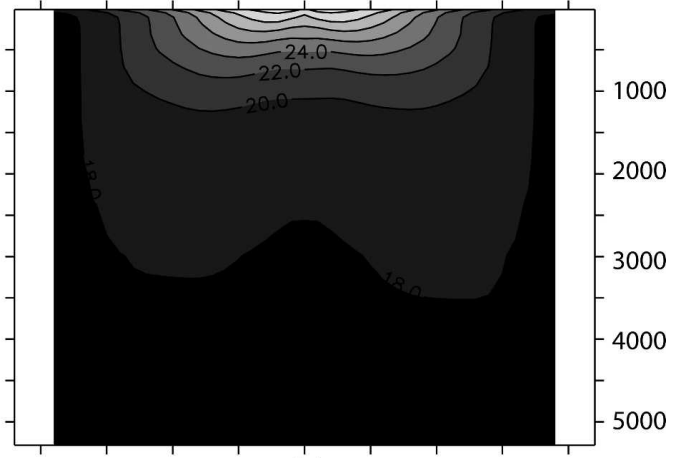

b)

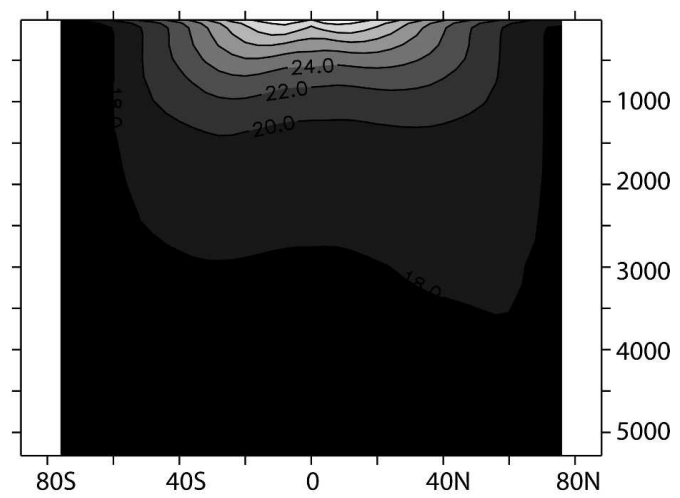

d)

FIG. 17. (a), (c) Horizontal streamfunctions (Sv, positive clockwise) and (b), (d) zonally averaged temperature vs depth $\left({ }^{\circ} \mathrm{C}\right)$ for (top) RidgeWorld and (bottom) DrakeWorld.

\section{RidgeWorld and DrakeWorld}

We now turn to what happens when the ocean circulation is forced into different regimes through the use of physical barriers. Two further scenarios are investigated. The first, RidgeWorld, has a thin meridional strip of land that runs from the North to South Pole, blocking circumglobal flow at all latitudes. This scenario is modified with a gap in the ridge near the South Pole to form the second scenario, DrakeWorld.

Both of these scenarios have a similar climate to that of WaterWorld, with high humidities and warm, shallow equator-to-pole surface temperature distributions. Analyzing them with the analytical model [Eqs. (1)(5)], produces very similar numbers, showing the general similarity to the WaterWorld scenario.

The inclusion of a barrier in the ocean dramatically changes the ocean circulation. RidgeWorld's single global basin develops a gyre structure analogous to those seen in zonally bounded ocean basins today (Fig. 17a), while DrakeWorld has the same gyres in the Northern Hemisphere but an analog of today's ACC in the Southern Hemisphere (Fig. 17b). The westward flow of the ACC on DrakeWorld can be traced to the surface zonal wind structure seen in all the idealized scenarios (e.g., as in Fig. 5) as the latitude of the broad gap in this case places the circumpolar flow under easterly winds. The change in basin configuration also significantly changes the vertical temperature structure in these oceans and both have far more of a thermocline than the WaterWorld case (Figs. 17c,d). This is consistent with the basic concept of baroclinic spinup (e.g., Anderson and Gill 1975) where baroclinic Rossby waves work westward from the eastern boundary, concentrating the horizontal circulation in the surface layers.

The RidgeWorld and DrakeWorld scenarios both have significantly different rainfall patterns to the zonally even one seen on WaterWorld, despite a lack of direct orographic forcing (Fig. 18). The barrier allows the formation of both an equatorial warm pool and strong boundary currents at the western side of the basin-the warm pool greatly increases the surface heat flux there, while the boundary currents carry warm tropical waters farther northward than found on WaterWorld, also leading to anomalously high surface fluxes. Both of these anomalous flux patches are collocated with rainfall maxima in both RidgeWorld and 


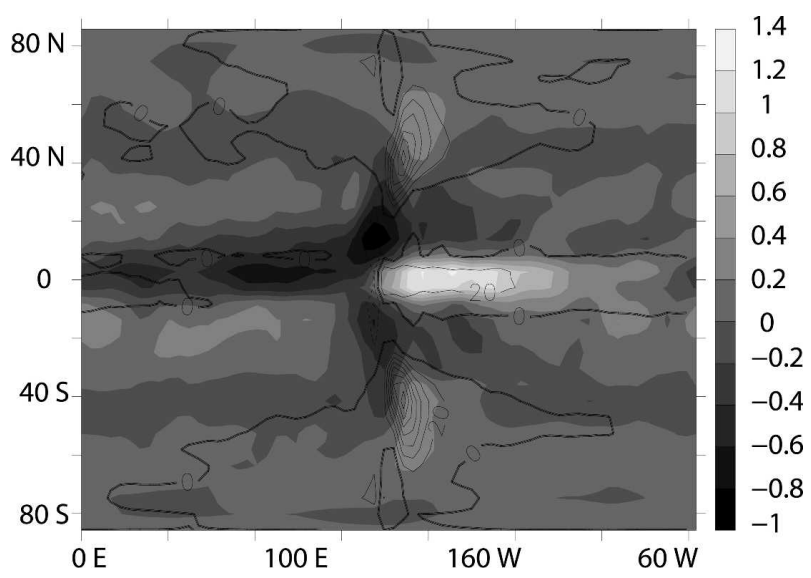

FIG. 18. Anomalous rainfall (shading, $\mathrm{m} \mathrm{yr}^{-1}$ ) and surface fluxes (contours, $\mathrm{W} \mathrm{m}^{-2}$ ), between RidgeWorld and WaterWorld.

DrakeWorld. However, there is little change in freshwater forcing at higher latitudes where it might be expected to impact on deep-water formation processes.

There are naturally significant differences in the MOCs for the scenarios. RidgeWorld is able to support zonally integrated geostrophic meridional flow throughout the basin, leading to sinking at both poles and a hemispherically symmetric overturning pattern (Fig. 19). The high apparent strength of this circulation is attributable to the large basin dimensions, density gradients and the value of the vertical diffusivity used, in accordance with scaling arguments in Klinger and Marotzke (1999). DrakeWorld's solution is similar in the Northern Hemisphere, but the Southern Hemisphere cell is cut off by the lack of zonal pressure gradient at the open gap (Fig. 19).
The hemispheric symmetry of the RidgeWorld MOC, and the fact that the DrakeWorld overturning has no real cross equatorial transport is interesting in the light of studies that suggest that models not tied to restoring boundary conditions tend to be unstable in such modes, collapsing into modes with one dominant hemisphere with global influence (e.g., Bryan 1986; Marotzke and Willebrand 1991). This is clearly not the case here. An explanation may be found by following the method of Hirschi et al. (2003), which can be used to assess the influence on the MOC of wind forcing and of density gradients separately. Further splitting the density gradient (thermal wind) term into the separate contributions from temperature and salinity shows that the overturning modes in both the RidgeWorld and DrakeWorld cases are dominated by the thermal contribution. They are thus rather insensitive to the small changes in water flux conditions that usually collapse the overturning into other modes, and retain their hemispherically confined character. For this reason, this paper focuses mainly on the thermal aspects of the climate system and has less to say about salinity effects.

The OHT found for the RidgeWorld scenario is now more clearly related to the MOC, with a hemispherically symmetric poleward transport of up to $1.6 \mathrm{PW}$. Despite the radical change in configuration, RidgeWorld's OHT has a form and magnitude that is very similar to WaterWorld's (Fig. 20). While much of this transport is due to the overturning component of the OHT, poleward of $20^{\circ}$ in both hemispheres the advective components start to decrease while the diffusive transport seen in the WaterWorld scenario increases, up to a maximum strength of around 0.4 PW. The subtropical gyre component of the OHT in these two sce-

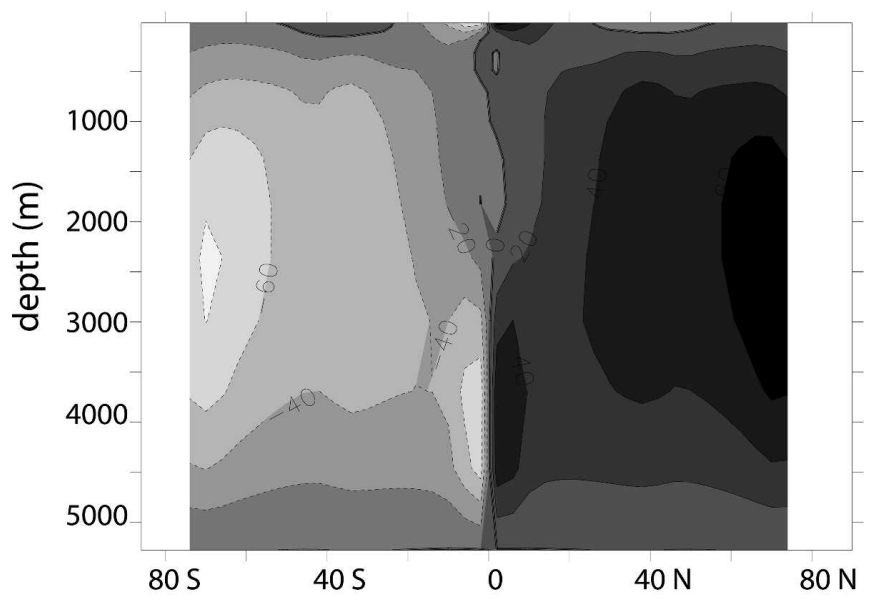

a)



b)

FIG. 19. Meridional overturning streamfunction (Sv, positive clockwise) for (a) RidgeWorld and (b) DrakeWorld. 




FIG. 20. Ocean heat transports for WaterWorld (dashed), RidgeWorld (heavy), and DrakeWorld (light).

narios, although far smaller than the overturning component, is interesting in that it transports heat equatorward, not poleward as would be expected from the collocation of the boundary current and the warm pool on the western side of the basin. This equatorward transport is due to the wind-driven upwelling of the cold deep return flow that occurs on the western side of the basin around $30^{\circ}$, which is then entrained into the northward boundary current, resulting in a small net equatorward transport.

The DrakeWorld scenario combines the two flow regimes of WaterWorld and RidgeWorld, and this is reflected in the OHT picture as well. In the Northern Hemisphere, very little difference is seen in the total OHTs of RidgeWorld and DrakeWorld, although, north of $20^{\circ} \mathrm{N}$, DrakeWorld sees an increase in southward transport by the gyre component and an increase of the northward mean overturning transport that cancel almost perfectly. In the Southern Hemisphere, the reduction in the MOC on DrakeWorld means that the overturning component of the OHT south of $20^{\circ} \mathrm{S}$ drops off faster than on RidgeWorld-it is almost zero at the latitude of the gap $\left(58^{\circ} \mathrm{S}\right)$. The reduction in overturning transport for DrakeWorld is exacerbated by an increase in northward heat transport by the Southern Hemisphere gyres. This drop in advective transport is, however, partially mitigated by an increase in the southward transport of the diffusive component on DrakeWorld, which compensates for about half of the reduction in advective transport, compared to RidgeWorld (Fig. 20). The diffusive component of the OHT in both these scenarios is much smaller than for WaterWorld; although the meridional temperature gradient is slightly different, the shallower thermoclines of RidgeWorld and DrakeWorld reduce the area over which it the diffusion is effective.

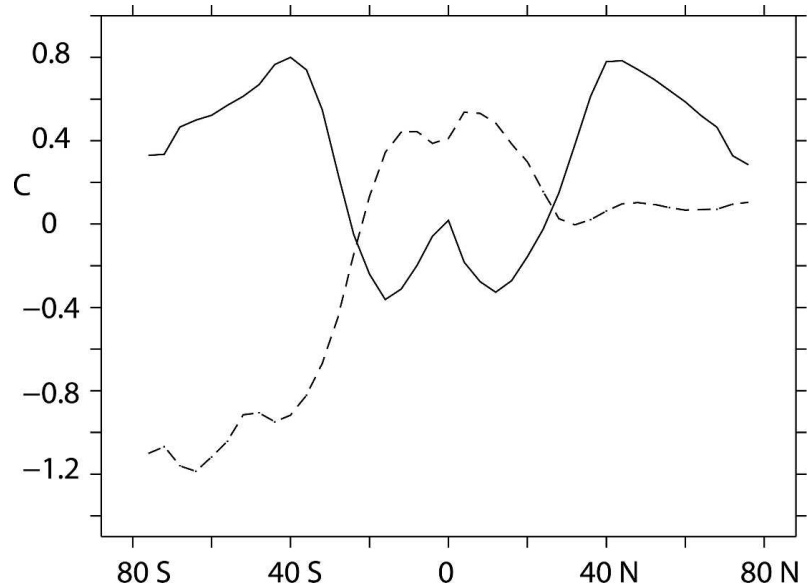

FIG. 21. SST differences between RidgeWorld and WaterWorld (solid) and DrakeWorld and RidgeWorld (dashed).

The differences of about $0.4 \mathrm{PW}$ in peak OHT between the different runs do not produce large differences in the SST profiles, consistent with the idea that ocean transport is not a primary control of surface temperature for these aquaplanets. RidgeWorld's increased poleward OHT, compared to WaterWorld reduces its meridional SST gradient by, at most, $1^{\circ} \mathrm{C}$ (Fig. 21). DrakeWorld has a similar temperature profile to RidgeWorld in the Northern Hemisphere, and the drop in OHT in the Southern Hemisphere produces a reduction in temperature of no more than $1.2^{\circ} \mathrm{C}$. The increased Southern Hemisphere temperature gradient on DrakeWorld does however lead to an increase in surface wind speeds, substantially increasing the flow of the (westward) "ACC" compared to the flow seen at similar latitudes on WaterWorld. There is some compensation seen in the AETs in these scenarios too, with the slight increase of up to $0.35 \mathrm{PW}$ in OHT going from WaterWorld to RidgeWorld being mirrored by a small decrease in AET, and the decrease in OHT at the gap in DrakeWorld of about the same magnitude seeing a corresponding increase in AET.

In some sense, the opening of the gap and resultant reduction in OHT in going from RidgeWorld to DrakeWorld is a milder version of the swamp WaterWorld experiment, where OHT is completely inhibited everywhere. We might thus expect to see similar mechanisms to those in the swamp WaterWorld when considering the reduction of Southern Hemisphere SSTs on DrakeWorld. This is partially the case, as high southern latitudes on DrakeWorld do see a decrease in columnintegrated water vapor like the high latitudes on the swamp WaterWorld. However, on DrakeWorld the total cloud fraction at these latitudes actually increases (mostly midlevel cloud), as does the TOA outgoing 
longwave over the gap region, despite the surface cooling. This is another example of the dynamic water vapor feedback of Herweijer et al. (2005), showing the importance of the system transports in determining surface temperatures.

\section{Discussion}

The difference in climate between the coupled and uncoupled WaterWorld shows a dramatic interaction of the global ocean circulation with the mean climate, extending well beyond redistributing heat and altering temperature gradients. The atmospheric feedbacks effects shown here confirm mechanisms previously found in other studies (Herweijer et al. 2005; Winton 2003; Clement et al. 1996) and suggest that they are robust features of the climate system present even under extreme forcing conditions.

A number of studies have been conducted on the possibility that the overall ocean + atmosphere energy transport for the climate is fixed by a few very basic parameters, so that changes in the system (that do not affect these largely inherent parameters) that influence one component of the transport result in a compensatory change in the other component (Bjerknes 1964; Manabe et al. 1975; Clement and Seager 1999; Winton 2003). Under the very different conditions simulated here, this is idea is found to have some meritWaterWorld has a very similar total energy transport to the modern reference, RidgeWorld, and DrakeWorld-and the changes in OHT between the three aquaplanets, although small, are compensated for by changes in atmospheric energy transport. The climatic impact of the OHT changes, particularly in the DrakeWorld case, is further mitigated by a change in radiative conditions that is arguably linked with the transport change (the dynamic longwave greenhouse feedback seen over the gap). However, the "constant system transport" hypothesis is seen at its weakest when comparing the coupled and swamp WaterWorld scenarios, where the ocean transport is completely inhibited. Here the atmospheric transport does increase somewhat, but fails to respond to the extreme changes, suggesting that there are limits to the degree of compensation available in the system. In this case, the planetary albedo of the system does change-changing one of the parameters required to remain constant in Stone (1978)'s analysis-but it may also be that the transport processes, particularly baroclinic eddies in the midlatitudes in this coarse-resolution model are not dynamically efficient enough to carry the full meridional transport required in this extreme case.

Some compensation occurs between the OHT com- ponents, primarily between the overall advective part of the transport and the diffusive component, which is a representation of the eddy fluxes. The lack of a robust eddy parameterization in the model is an especial weakness, particularly for the cases of WaterWorld and the gap of DrakeWorld where eddy transports would be expected to be significant in the real world, and the results for these scenarios here must be analyzed with due caution. Although tests with a GM-enabled model here suggest that the Cartesian mixing model setup here appears to obtain a qualitatively correct answer, it is questionable as to whether this "right" answer is obtained for the right reasons, and any deeper studies along these lines should undoubtedly use some form of eddy parameterization. Given the similarity of the results from the GM-enabled model, although the coarse resolution and nature of the ocean mixing parameterization used here undoubtedly overestimate the degree of horizontal mixing, we do not think that the effects seen here are purely numerical artifacts, nor that the inaccuracy in the representation of mixing invalidates the other climatic feedbacks.

The results of the analytic radiative model shows that the behavior of the atmosphere in different cases (the modern reference, the coupled WaterWorld, and the swamp WaterWorld) is characterized by very different parameter values, which could not easily be obtained from any a priori consideration. This is particularly true of the two WaterWorld cases, where there has been no change at all in specified surface properties. Results from an idealized Pangean climate (Smith et al. 2004) analyzed in the same way reinforce this concept further: here an increase in surface albedo as compared to modern conditions leads, through changes in the radiative properties of the atmosphere, to an decrease in the planetary albedo, and a consequent warming of the planet. Many simpler climate models, especially energy balance models (North and Coakley 1981), have a climatic behavior which is the result of parameter values chosen by tuning to match one particular climate state. The qualitative differences in the radiative model characteristics obtained here for the different cases suggests that the use of highly reduced or parameterized atmosphere models for long time-scale integrations may need to be initially guided by an explicit GCM study. This would allow correct parameter values to be obtained without having to rely on scaling from an initial, different climate state that may not produce the correct behavior.

An important potential effect of the global OHT on climate is its influence on the extent of sea ice (e.g., Seager et al. 2002; Winton 2003), and that has been 
proposed as a likely player in theories of major climate changes such as the glacial cycle. This plays no part in the experiments presented here because the inherent warmth of all the scenarios inhibits sea ice formation, so an important climate feedback is inactive in these idealized studies.

\section{Conclusions}

1) This study looks at the climates and coupled feedbacks that result from a small suite of successful OAGCM experiments with aquaplanet-type scenarios, the first of their kind. The climates found have strong water vapor greenhouses, probably triggered by the reduction in surface albedo although in equilibrium the planetary shortwave balance is identical to that of a modern reference. Radiative forcing, through changes in column water vapor caused by both local effects and changes in atmospheric circulation is found to be the primary control on both the surface climate and circulations of atmosphere and ocean, with haline forcing playing only a minor role in the ocean.

2) The hypothesis of a constant system heat transport, proposed by (among others) Bjerknes (1964) and Stone (1978) is found to hold under this extreme test for small variations in OHT. Where OHT is entirely inhibited it fails as changes in the system result in a change of the planetary albedo and the conditions required for this constancy are violated. Feedbacks that provide for the capping of equatorial SSTs and mechanisms for the OHT to affect global mean climate via atmospheric effects proposed by others are found to be more robust.



a)
3) When a simple analytical energy balance model is tuned to the atmospheric behavior produced in each case, the parameters of the simple model are qualitatively different in each case, in ways that are not a priori predictable from the changes in scenario made. Hence, simpler atmospheric models need to be carefully guided by the application of more sophisticated GCMs before being applied to different configurations.

Acknowledgments. This work formed part of a Ph.D. thesis at the Southampton Oceanography Centre and was funded as part of a UK NERC Ph.D. studentship with a contribution from the Max-Planck Institute for Meteorology, Hamburg, Germany. We thank Joel Hirschi and Bablu Sinha for useful discussions, both climatological and technical, and Richard Seager and numerous anonymous reviewers for their helpful comments.

\section{APPENDIX}

\section{FORTE's Coarse-Resolution "Modern" Climate Simulation}

The results shown here are from a 700-yr run of the low-resolution FORTE model with a modern geography. Prior to coupling, the models had been spun up to equilibrium with surface restoring to Levitus et al. (1998). No model parameter retuning had been done nor flux adjustments applied, although these can be used for more accurate simulation of modern climate. The results are presented here to provide a reference for investigating the effects purely of changing model geometry, and also to help assess likely biases in the



b)

FIG. A1. Annual average (a) surface air temperature $\left({ }^{\circ} \mathrm{C}\right.$ ) and (b) sea surface salinity (psu) for the nonflux-adjusted current climate simulation after $700 \mathrm{yr}$. 


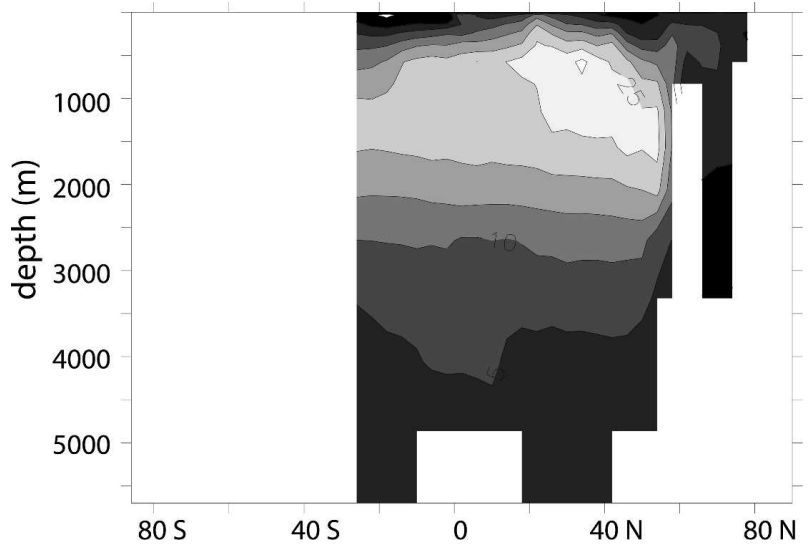

FIG. A2. Atlantic MOC (Sv, positive clockwise) for the nonflux-adjusted current climate simulation after $700 \mathrm{yr}$.

model. This integration has not been run to equilibrium, and there is an average $4.1 \mathrm{~W} \mathrm{~m}^{-2}$ imbalance at the top of the atmosphere-this bias has been removed from the total energy transport derived from TOA fluxes in Fig. 8 by assuming correcting for this average imbalance at every grid point.

As can be seen, there are many recognizable features in the simulation. In general however the Tropics are too cool, a result of too broad a wind-driven upwelling at the equator, and the poles are too warm, which leads to a paucity of sea ice (Fig. A1). The meridional surface temperature gradient is not, however, as shallow as that seen for the idealized results. The model retains a salinity difference between the Atlantic and Pacific (Fig. A1). The MOC seen in the Atlantic is of the correct form, although rather too strong and with no evidence of Antarctic Bottom Water penetration into the basin (Fig. A2). Most anomalously, despite the fresh surface waters there is some overturning in the Pacific basin.

\section{REFERENCES}

Anderson, D. L. T., and A. E. Gill, 1975: Spin-up of a stratified ocean, with application to upwelling. Deep-Sea Res., 22, 583596.

Betts, A., 1986: A new convective adjustment scheme. 1. Observational and theoretical basis. Quart. J. Roy. Meteor. Soc., 112, 667-691.

Bjerknes, J., 1964: Atlantic air-sea interactions. Advances in Geophysics, Vol. 10, Academic Press, 1-82.

Bjornsson, H., and J. Toggweiler, 2001: The climatic influence of Drake Passage. The Oceans and Rapid Climate Change: Past, Present and Future. Geophys. Monogr., Vol. 126, Amer. Geophys. Union, 243-259.

Broecker, W., D. Peteet, and D. Rind, 1985: Does the oceanatmosphere system have more than one stable mode of operation? Nature, 315, 21-26.

Bryan, F., 1986: High-latitude salinity effects and interhemispheric thermohaline circulations. Nature, 323, 301-304.
Bryan, K., S. Manabe, and R. C. Pacanowski, 1975: A global ocean-atmosphere climate model. Part II: The oceanic circulation. J. Phys. Oceanogr., 5, 30-46.

Clement, A. C., and R. Seager, 1999: Climate and the tropical oceans. J. Climate, 12, 3383-3401.

,-- M. A. Cane, and S. E. Zebiak, 1996: An ocean dynamical thermostat. J. Climate, 9, 2190-2196.

Cox, M. D., 1989: An idealized model of the world ocean. Part I: The global-scale water masses. J. Phys. Oceanogr., 19, 17301752.

Forster, P. D. F., M. Blackburn, R. Glover, and K. Shine, 2000: An examination of climate sensitivity for idealised climate change experiments in an intermediate general circulation model. Climate Dyn., 16, 833-849.

Gent, P., and J. McWilliams, 1990: Isopycnal mixing in ocean circulation models. J. Phys. Oceanogr., 20, 150-155.

— J. Jillebrand, T. McDougall, and J. McWilliams, 1995: Parameterizing eddy-induced transports in ocean circulation models. J. Phys. Oceanogr., 25, 463-474.

Gill, A. E., and K. Bryan, 1971: Effects of geometry on the circulation of a three-dimensional southern-hemisphere ocean model. Deep-Sea Res., 18, 685-721.

Gordon, C., C. Cooper, C. Senior, H. Banks, J. Gregory, T. Johns, J. F. B. Mitchell, and R. Wood, 2000: The simulation of SST, sea ice extents and ocean heat transports in a version of the Hadley Centre coupled model without flux adjustments. Climate Dyn., 16, 147-168.

Heinrich, H., 1988: Origin and consequences of cyclic ice rafting in the northeast Atlantic Ocean during the past 130000 years. Quat. Res., 29, 143-152.

Herweijer, C., R. Seager, M. Winton, and A. Clement, 2005: Why ocean heat transport warms the global mean climate. Tellus, 57A, 662-675.

Hirschi, J., J. Baehr, J. Marotzke, J. Stark, S. Cunningham, and J.-O. Beismann, 2003: A monitoring design for the Atlantic meridional overturning circulation. Geophys. Res. Lett., 30, 1413, doi:10.1029/2002GL016776.

Hoskins, B., and A. Simmons, 1975: A multi-layer spectral model and the semi-implicit method. Quart. J. Roy. Meteor. Soc., 101, 637-655.

Houghton, J. T., Y. Ding, D. J. Griggs, M. Noguer, P. J. van der Linden, and D. Xiaosu, Eds., 2001: Climate Change 2001: The Scientific Basis. Cambridge University Press, 944 pp.

Jungclaus, J. H., and Coauthors, 2006: Ocean circulation and tropical variability in the coupled model ECHAM5/MPIOM. J. Climate, 19, 3952-3972.

Klein, S., and D. Hartmann, 1993: The seasonal cycle of low stratiform cloudiness. J. Climate, 6, 1587-1606.

Klinger, B. A., and J. Marotzke, 1999: Behavior of doublehemisphere thermohaline flows in a single basin. J. Phys. Oceanogr., 29, 382-399.

Levitus, S., and Coauthors, 1998: Introduction. Vol. 1, World Ocean Database 1998. NOAA Atlas NESDIS 18, 346 pp.

Manabe, S., K. Bryan, and M. J. Spelman, 1975: A global oceanatmosphere climate model. Part I: The atmospheric circulation. J. Phys. Oceanogr., 5, 3-29.

Marotzke, J., and J. Willebrand, 1991: Multiple equilibria of the global thermohaline circulation. J. Phys. Oceanogr., 21, 13721385.

Marsland, S., H. Haak, J. Jungclaus, M. Latif, and F. Rske, 2003: The Max-Planck Institute global ocean/sea-ice model with orthogonal curvilinear coordinates. Ocean Modell., 5, 91-127.

McManus, J., R. Francois, J.-M. Gherardi, L. Keigwin, and S. 
Brown-Leger, 2004: Collapse and rapid resumption of Atlantic meridional circulation linked to deglacial climate changes. Nature, 428, 834-837.

Munk, W., and C. Wunsch, 1998: Abyssal recipes II: Energetics of tidal and wind mixing. Deep-Sea Res., 45A, 1977-2010.

Neale, R., and B. Hoskins, 2000: A standard test for AGCMs including their physical parametrizations. II: Results for the Met. Office model. Atmos. Sci. Lett., 1, 108-114.

North, G. R., R. F. Calahan, and J. A. Coakley, 1981: Energybalance climate models. Rev. Geophys. Space Phys., 19, 91121.

Pacanowski, R., 1987: Effect of equatorial currents on surface stress. J. Phys. Oceanogr., 17, 833-838.

_, K. Dixon, and A. Rosati, 1991: The GFDL modular ocean model users guide: Version 1.0. Tech. Rep. 2, NOAA/ Geophysical Fluid Dynamics Laboratory, Princeton University, $44 \mathrm{pp}$.

Pierrehumbert, R., 1995: Thermostats, radiator fins and the local runaway greenhouse. J. Atmos. Sci., 52, 1784-1806.

Ramanathan, V., and W. Collins, 1991: Thermodynamic regulation of ocean warming by cirrus clouds deduced from observations of the 1987 El Niño. Nature, 351, 27-32.

Roeckner, E., and Coauthors, 2003: The atmospheric general circulation model ECHAM5. Rep. 349, Max-Planck Institute for Meteorology, Hamburg, Germany, 127 pp.

Sausen, R., and R. Voss, 1996: Techniques for asynchronous and periodically synchronous coupling of atmosphere and ocean models. Climate Dyn., 12, 313-323.

Seager, R., D. Battisti, J. Yin, N. Gordon, N. Naik, A. Clement, and M. Cane, 2002: Is the Gulf Stream responsible for Europe's mild winter. Quart. J. Roy. Meteor. Soc., 128, 1-24.

Sinha, B. S., and R. S. Smith, 2002: Development of a fast coupled general circulation model (FORTE) for climate studies, implemented using the OASIS coupler. Tech. Rep. 81, Southampton Oceanography Centre, $67 \mathrm{pp}$.

Slingo, J., 1987: The development and verification of a cloud prediction scheme for the ECMWF model. Quart. J. Roy. Meteor. Soc., 113, 899-927.

Smith, R. S., 2004: Ocean circulation and climate dynamics under idealised continental configurations in a coupled oceanatmosphere model. Ph.D. thesis, University of Southampton, 199 pp.

— C. Dubois, and J. Marotzke, 2004: Ocean circulation and climate in an idealised Pangean OAGCM. Geophys. Res. Lett., 31, L18207, doi:10.1029/2004GL020643.

Stone, P. H., 1978: Constraints on dynamical transports of energy on a spherical planet. Dyn. Atmos. Oceans, 2, 123-139.

Terray, L., S. Valcke, and A. Piacentini, 1999: OASIS 2.3 user's guide. Tech. Rep. TR/CGMC/99-37, CERFACS, Toulouse, France, $82 \mathrm{pp}$.

Trenberth, K. E., and J. M. Caron, 2001: Estimates of meridional atmosphere and ocean heat transports. J. Climate, 14, 34333442.

Weaver, A. J., and Coauthors, 2001: The UVic Earth System Climate Model: Model description, climatology and applications to past, present and future climates. Atmos.-Ocean, 39, 361428 .

Webb, D., 1996: An ocean model code for array processor computers. Comput. Geosci., 22, 569-578.

- B. deCuevas, and A. Coward, 1998: The first main run of the OCCAM global ocean model. Tech. Rep. 34, Southampton Oceanography Centre, $43 \mathrm{pp}$.

Winton, M., 2003: On the climatic impact of ocean circulation. $J$. Climate, 16, 2875-2889. 